\title{
Evaluating the effects of high penetrations of roof-top wind Turbines on secondary distribution circuits
}

DOI:

10.1109/TDCLA.2006.311476

Link to publication record in Manchester Research Explorer

\section{Citation for published version (APA):}

Kritharas, P. P., Ochoa, L. F., Papastergiou, K. D., \& Harrison, G. P. (2006). Evaluating the effects of high penetrations of roof-top wind Turbines on secondary distribution circuits. In 2006 IEEE PES Transmission and Distribution Conference and Exposition: Latin America, TDC'06/IEEE PES Transm. Distrib. Conf. Expo.: Latin America, TDC https://doi.org/10.1109/TDCLA.2006.311476

\section{Published in:}

2006 IEEE PES Transmission and Distribution Conference and Exposition: Latin America, TDC'06|IEEE PES Transm. Distrib. Conf. Expo.: Latin America, TDC

\section{Citing this paper}

Please note that where the full-text provided on Manchester Research Explorer is the Author Accepted Manuscript or Proof version this may differ from the final Published version. If citing, it is advised that you check and use the publisher's definitive version.

\section{General rights}

Copyright and moral rights for the publications made accessible in the Research Explorer are retained by the authors and/or other copyright owners and it is a condition of accessing publications that users recognise and abide by the legal requirements associated with these rights.

\section{Takedown policy}

If you believe that this document breaches copyright please refer to the University of Manchester's Takedown Procedures [http://man.ac.uk/04Y6Bo] or contact uml.scholarlycommunications@manchester.ac.uk providing relevant details, so we can investigate your claim.

\section{OPEN ACCESS}




\title{
Evaluating the Effects of High Penetrations of Roof-Top Wind Turbines on Secondary Distribution Circuits
}

\author{
Petros P. Kritharas, Luis F. Ochoa, Student Member, IEEE, Konstantinos D. Papastergiou, Student \\ Member, IEEE, and Gareth P. Harrison, Member, IEEE
}

\begin{abstract}
Incentives for using wind power and the increasing price of energy might generate in a relatively short time a scenario where low voltage customers opt to install roof-top wind turbines. This paper focuses on evaluating the effects of such situation in terms of energy consumption, loss reduction, reverse power flow and voltage profiles. Various commercially-available roof-top wind turbines are installed in two secondary distribution circuits considering real-life wind speed data and seasonal load demand. Results are presented and discussed.
\end{abstract}

Index Terms - distributed generation, roof-top wind turbines, distribution networks, power flow, line losses.

\section{INTRODUCTION}

$\mathrm{C}$ URRENT energy policies are encouraging the connection $C_{\text {of }}$ small-scale power generating plants to distribution networks, mainly in response to environmental concerns as well diversification of the energy mix. As such, Distributed Generation (DG) [1], electric power generation located within distribution networks or on the customer side of the network, is expected to play an increasingly important role in the power system infrastructure and market. On the other hand, given that distribution networks were not planned to support widespread insertion of power, various studies have reported that such integration may create technical and safety problems [2]-[6].

Considering the special attention given by governments to wind energy, currently the fastest growing technology, and a scenario where residential and commercial customers harness the benefits of on-site generation, this work is aimed at assessing the effects that a high level penetration of roof-top wind turbines may produce on secondary distribution, i.e. low voltage, circuits. Moreover, given the time-variant characteristics of wind generation it will be necessary to examine impacts over an extended time period.

Here, two secondary distribution circuits are analyzed considering seasonal daily demands. Wind power estimates are based on data for southern Scotland for the year 2003.

P. P. Kritharas, K. D. Papastergiou and G. P. Harrison are with the School of Engineering and Electronics, University of Edinburgh, Institute for Energy Systems, Edinburgh, EH9 1NP, U.K.

L. F. Ochoa is with the Department of Electrical Engineering, UNESP (Universidade Estadual Paulista), Ilha Solteira, SP, Brazil.

e-mails: petkri@gmail.com, luis_ochoa@ieee.org, pap@iieee.org and Gareth.Harrison@ed.ac.uk.
Results are presented and discussed remarking the timevariant benefits and drawbacks of roof-top wind power generation taking into account critical scenarios of such generation.

\section{TECHNicAl DATA}

In this section the data required for performing the simulations of high penetrations of roof-top wind turbines in secondary distribution circuits is presented. This includes wind turbine power curves, wind speeds, load demand and secondary circuit details.

\section{A. Wind Turbines and Wind Speed Data}

In order to consider real-life roof-top wind turbines, five types that can easily be found in the market were chosen, as shown in Table I.

TABLE I

SELECTED COMMERCIAL WIND TURBINES

\begin{tabular}{|c|c|c|c|}
\hline Type & $\begin{array}{c}\text { Nominal } \\
\text { Output }(k W)\end{array}$ & Type of Generator & $\begin{array}{l}\text { Operational Wind } \\
\text { Speed Range }(\mathrm{m} / \mathrm{s})\end{array}$ \\
\hline AIR-X ${ }^{1}$ & 0.4 & Permanent magnet & $3-20$ \\
\hline Fortis Espada (FE) ${ }^{2}$ & 0.8 & Permanent magnet & $3-25$ \\
\hline $\mathrm{BWC} \mathrm{XL1}^{3}$ & 1.0 & Permanent magnet & $3-20$ \\
\hline SWIFT $^{4}$ & 1.5 & Permanent magnet & $3-25$ \\
\hline WES5 Tulipo (WES5) ${ }^{5}$ & 2.5 & Induction generator & $3-20$ \\
\hline
\end{tabular}

${ }^{1}$ Southwest Windpower [7], ${ }^{2}$ Fortis Windenergy [8], ${ }^{3}$ Bergey Windpower [9]

${ }^{4}$ Renewable Devices [10], ${ }^{5}$ Wind Energy Solutions [11]

Since each wind turbine is manufactured by different companies their performances vary. Fig. 1 shows the corresponding power output curves which are required for a time-variant analysis given the changing nature of wind speeds.

Wind speed data used in this work corresponds to hourly measurements carried out by the UK Meteorological Office for central Scotland for 2003. Although there is a strong dependence between wind speed and geographical position, solely one anemometer was chosen for the distribution secondary circuits to be tested since they represent small areas. Average daily wind speeds of the selected anemometer are presented in Fig. 2. 


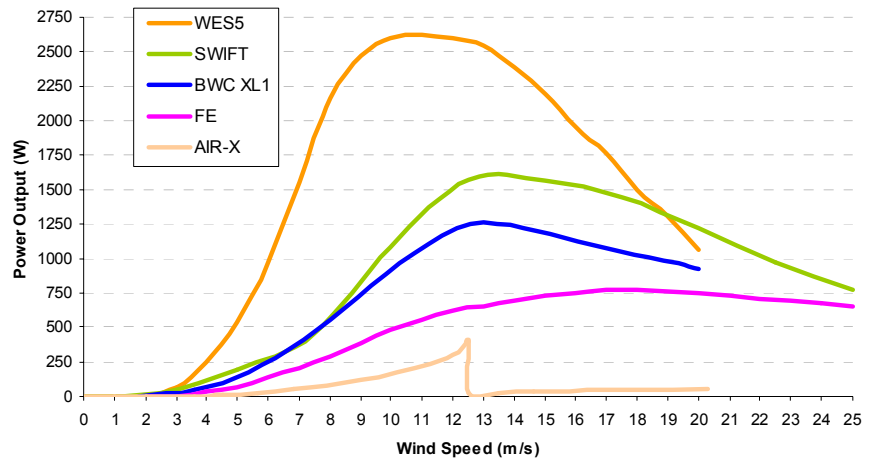

Fig. 1. Power output curves for the five selected wind turbines [7]-[11]

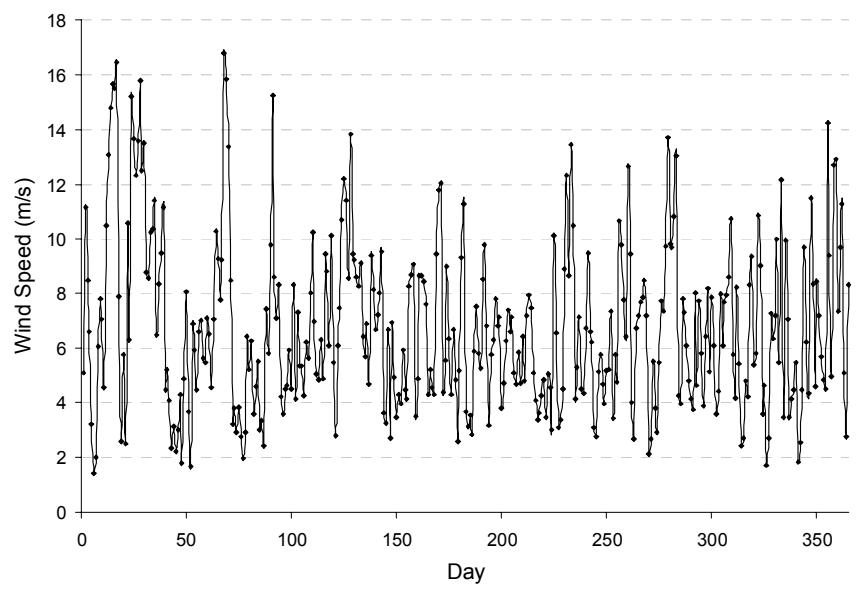

Fig. 2. Average daily wind speeds for 2003 - Central Scotland

Nonetheless, even being considered useful information average daily wind speeds just exhibit the wind power potential of a given geographic area. The impacts on the operational behavior of secondary circuits will be seen when analyzing critical scenarios such as the maximum daily generation which is obtained when, for a given wind turbine, "usable" wind speeds appeared throughout the day.

\section{B. Test Network and Load Demand}

Two low voltage distribution secondary circuits were used in order to evaluate the effects of high penetration of roof-top wind turbines. Both four-wire three-phase circuits possess a radial structure and line voltage of $240 \mathrm{~V}$. Line section and load data are presented in Appendix A. The 21-bus circuit which contains 16 residential loads accounting for a total maximum demand of $26.5 \mathrm{~kW}$, mainly using ASC $2 / 0$ conductors. The second circuit is composed by 29 buses, 12 of which are residential loads with a total maximum demand of $17.7 \mathrm{~kW}$, using ACSR \#2 conductors. Both secondary circuits will use the typical load profiles shown in Fig. 3, obtained after adjustment from the design values of peak demand to the actual average value of peak winter demand and minimum summer demand as reported by the Electricity Association in UK [12].

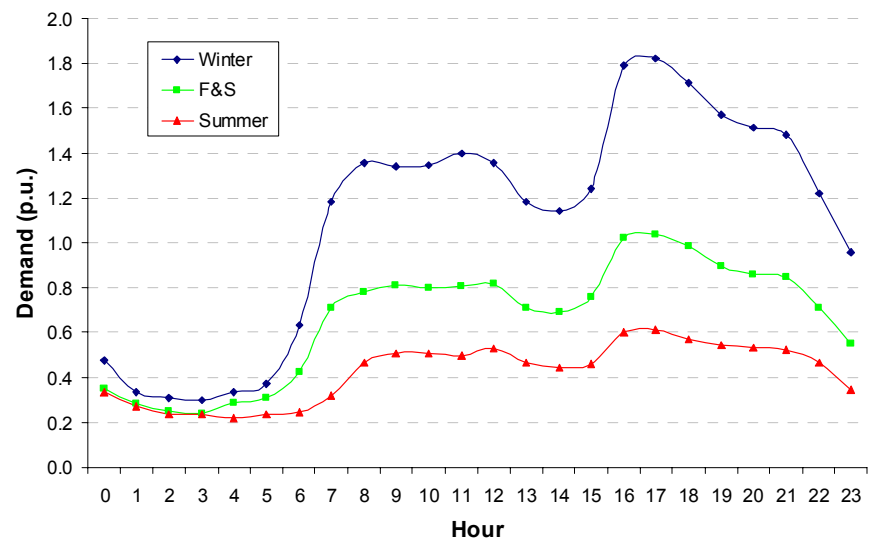

Fig. 3. Seasonal daily demand

\section{TEST AND RESULTS}

The four-wire three-phase power flow algorithm based on the backward/forward current summation technique from [13] was adopted. Load was modeled as constant power with wind turbine generation considered as negative load (power factor equal to unity).

Since the purpose of this work is to evaluate the effects of a high penetration of wind turbines, simulations carried out assume that 10 residential consumers each have a specific model of roof-top wind turbine. For the 29 -bus circuit, $63 \%$ of residential customers will have a roof-top wind turbine installed, whereas the figure is $83 \%$ for the 21 -bus circuit. The following subsections will describe different approaches to evaluate the effects of those wind turbines on the secondary distribution circuits.

\section{A. Energy}

Given the three seasonal demand patterns presented in Fig. 3 , i.e., summer, F\&S (fall and spring) and winter, Figures 4 and 5 show the 24-hour energy consumption of the day during which the output of each model of wind turbine was at its seasonal maximum on each of the 21-bus and 29-bus circuits, respectively. With different power curves for each turbine, the days shown are not necessarily the same for each device, as Table II indicates. The first values of energy consumptions ("NO WT") correspond to the original secondary circuits, i.e., no wind turbine installed.

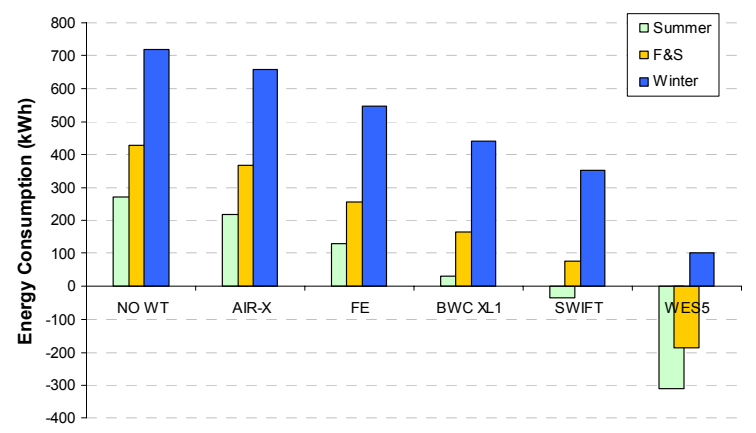

Fig. 4. Seasonal daily energy consumption for the maximum energy production day of the analyzed wind turbine considering the 21-bus circuit 


\section{Accepted Paper}

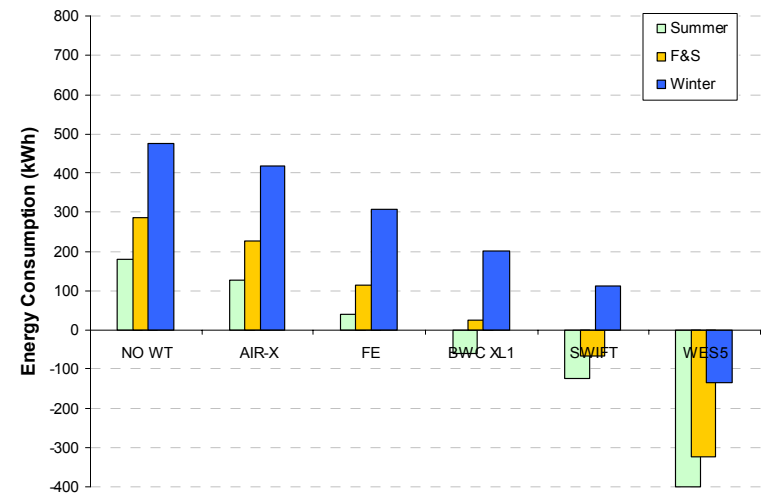

Fig. 5. Seasonal daily energy consumption for the maximum energy production day of the analyzed wind turbine considering the 29-bus circuit

TABLE II

DATE FOR THE MAXIMUM DAILY ENERGY PRODUCTION FOR 2003

\begin{tabular}{|c|c|c|c|}
\cline { 2 - 4 } \multicolumn{1}{c|}{} & Summer & F\&S & Winter \\
\hline AIR-X & 01-Jul & 06-May & 02-Jan \\
\hline FE & 21-Aug & 10-Mar & 15-Jan \\
\hline BWC XL1 & 01-Jul & 06-May & 21-Dec \\
\hline SWIFT & 01-Jul & 10-Mar & 21-Dec \\
\hline WES5 & 01-Jul & 06-May & 02-Feb \\
\hline
\end{tabular}

As expected, the more the nominal capacity insertion of wind turbines, the less the energy consumed by the circuits. Moreover, in some cases the wind power generation exceed the circuit demand, leading to a scenario were energy is exported. In this way, it can be seen in Fig. 5 that the insertion of 10 WES5 wind turbines (total nominal capacity of $25 \mathrm{~kW}$ ) is able to fully supply the 29-bus circuit demand and even export energy when considering the maximum daily energy production. Given that, in some cases, reverse power flow may disrupt the operation of distribution transformers, regular export of energy may not be desirable. In this way, $10 \mathrm{BWC}$ XL1 wind turbines (total nominal capacity of $10 \mathrm{~kW}$ ) may be suitable for the 21-bus circuit, whereas for the 29-bus solely 8 $\mathrm{kW}$ of total nominal capacity (10 FE wind turbines) may be installed.

Certainly, the insertion of wind turbines will relieve the load demand leading to a reduction of power losses. However, this statement is limited to a given generation capacity since losses may also increase, as shown in Fig. 6.

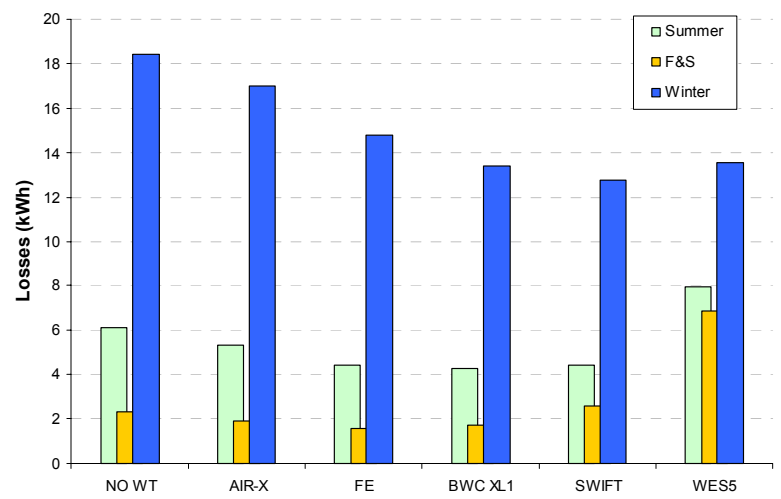

Fig. 6. Seasonal daily losses for the maximum energy production day of the analyzed wind turbine considering the 21 -bus circuit

\section{B. Total Power Flow Through the Distribution Transformer}

Even analyzing the total energy consumption, as presented in Fig. 4 and Fig. 5, some results may be masked due to the time-variant characteristic of both the demand and wind power generation. Therefore, an hourly analysis becomes a useful tool for observing the behavior of the total power flow through the distribution transformer.

Figures 7 to 9 present hourly power flows at the head of the circuit of those configurations where installed wind turbines did not produce negative daily energy consumption for the 21bus circuit (Fig. 4), considering summer, F\&S and winter seasons, respectively. Clearly, while some configurations remain demanding power from the distribution transformer throughout the day, some wind turbines do produce reverse power flows, confirming the importance of such a detailed approach. Consequently, for this secondary circuit it may be appropriate to install no more than $10 \mathrm{FE}$ wind turbines (total nominal capacity of $8 \mathrm{~kW}$, i.e., $30 \%$ capacity penetration), although small reverse power flows appear as it can be verified in Fig. 8.

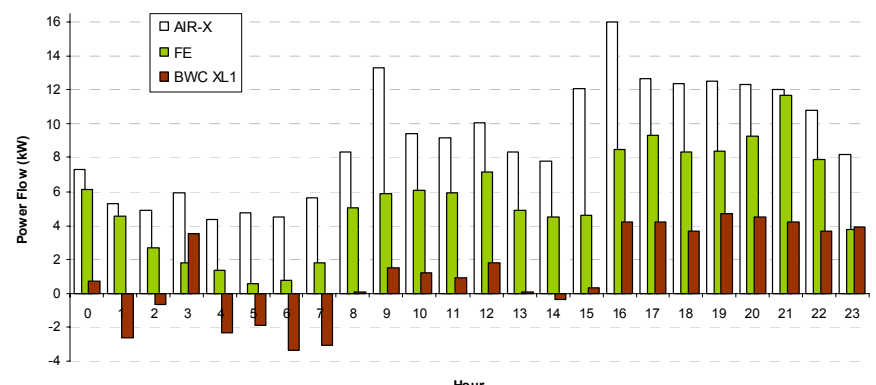

Fig. 7. Hourly power flows for the maximum energy production summer day of the analyzed wind turbine considering the 21 -bus circuit

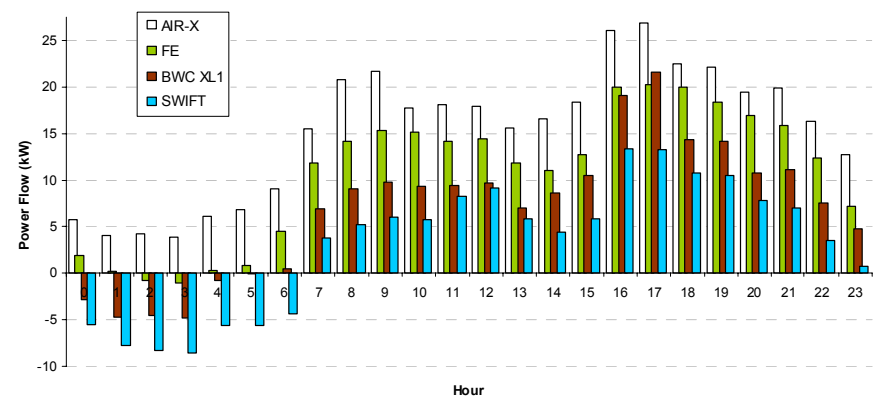

Fig. 8. Hourly power flows for the maximum energy production F\&S day of the analyzed wind turbine considering the 21 -bus circuit

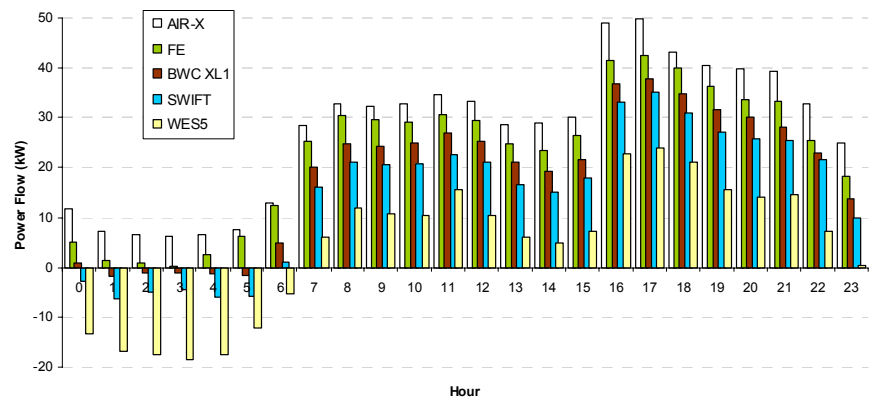

Fig. 9. Hourly power flows for the maximum energy production winter day of the analyzed wind turbine considering the 21-bus circuit 


\section{Accepted Paper}

\section{Three-phase Power Flow Through the Transformer}

It is well known that distribution systems present unsymmetrical line segments and unbalanced loads, i.e., unbalance is a common-day problem face by utilities. Consequently, the total power flow at the head of the circuit can be split into its three-phase components in order to gain a deeper insight.

Fig. 10 presents the hourly three-phase power flows for the maximum energy production summer day considering ten AIR-X wind turbines installed in the 21-bus circuit. Although Fig. 7 exhibits that there is no reverse total power flow, when having a per phase analysis one can find out that during some hours reverse power flow do take place for phases $b$ and $c$. It is important to remark that the 21-bus circuit is particularly unbalanced, with most loads in phase $a$. Consequently, since the wind power injection is assumed balanced among the three phases, the least loaded phases are more affected.

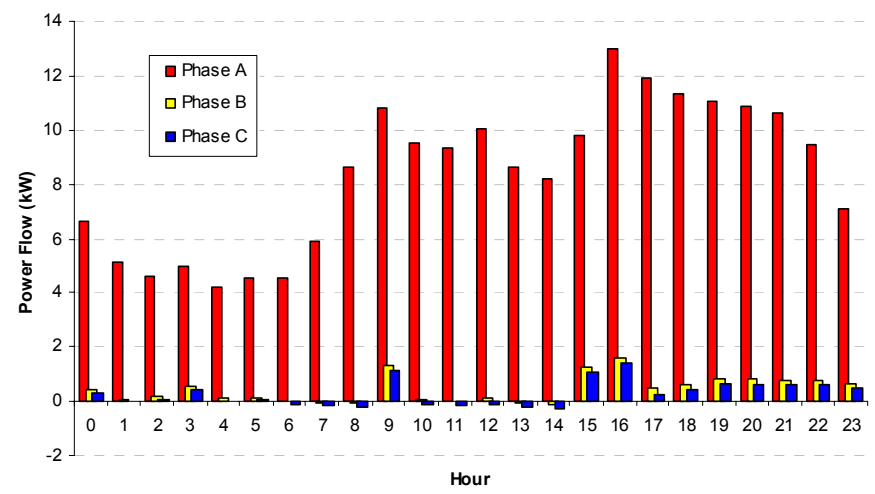

Fig. 10. Hourly three-phase power flows for the maximum energy production summer day for ten AIR-X wind turbines considering the 21-bus circuit

\section{Voltage Profile}

Decrease of losses and reverse power flows directly affect the voltage profile of the secondary circuit. Certainly, due to power quality issues the maintenance of voltages within specified limits is very important.

Fig. 11 shows the voltage profiles of the longest path in the 29-bus circuit considering three different sets of wind turbines during the hour of peak demand (17:00 - 18:00) of the maximum generation summer day. Phase $a$ was considered for analysis since the 29-bus circuit is reasonably well balanced. As expected, the original voltage profile ("NO WT") is improved by adding sets of ten AIR-X, SWIFT or BWC XL1 wind turbines. Nonetheless, the latter, due to the reverse power flow (see Fig. 5), exhibits voltages above that of the distribution transformer (node 1). On the other hand, if we are to consider voltage limits, for instance, $\pm 5 \%$, the largest voltage exceeds the reference voltage by $0.4 \%$.

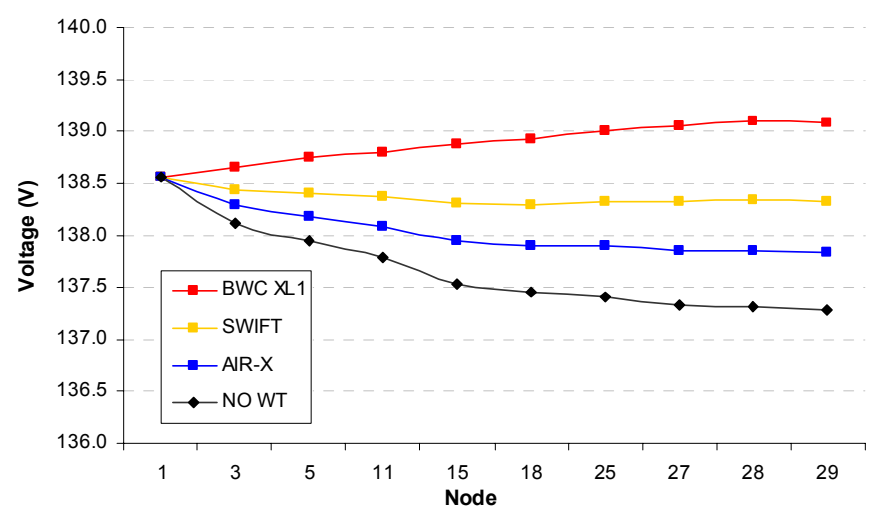

Fig. 11. Phase- $a$ voltage profiles of the longest path in the 29-bus circuit during the most loaded hour $(17: 00-18: 00)$ of maximum energy production summer day

\section{CONCLUSIONS}

This work presents an evaluation of the effects of high penetrations of roof-top wind turbines on secondary (low voltage) distribution circuits. Energy consumption, loss reduction, reverse power flows and voltage profile were analyzed considering sets of different commercially-available roof-top wind turbines.

As expected, results suggest that the higher the penetration the greater the reduction in losses in the secondary circuit. Nonetheless, when total demand is exceeded reverse power flows appear which may disrupt transformer operation. It was also shown that, due to load unbalance, which is common in distribution systems, a per phase analysis is needed. Voltage profiles are also improved by higher penetrations and given the relatively modest turbine capacities there is limited risk of breaching voltage limits.

Reverse power flow and voltage control strategies, as well as protection schemes should be also analyzed in scenarios with high penetration of wind turbines, considering both technical and economic aspects.

Finally, it is important to note that this study considered the maximum energy production day of each season, so the effects of the wind power generation are most significant. In practice, in order to investigate the impacts of wind turbines insertion in distribution networks it is critical the availability of wind speed forecasting for a given horizon, considering a longer period of time, as well as the uncertainties associated.

\section{APPENDIX A}

Table A-1a and Table A-1b present the corresponding line section data, self and mutual impedances, in ohms for the 21bus circuit. Corresponding load demand (representing 1.0 p.u.) is shown in Table A-2, where solely those nodes with load are included.

Table A-3 presents the corresponding line section data for the 29-bus circuit. Three-phase impedance matrices $Z_{1}, Z_{2}$ and $Z_{2}$, are required to compute all self and mutual impedance in ohms. Table A-4 shows the respective load demand (representing 1.0 p.u.). 
TABLE A-1 A Line SeCtion DATA $(\Omega)-21$-BUS CirCuit

\begin{tabular}{|c|c|c|c|c|c|c|}
\hline $\begin{array}{c}\text { Line } \\
\text { Section }\end{array}$ & Raa & Xaa & Rab & Xab & Rac & Xac \\
\hline $1-2$ & 0.0243 & 0.0246 & 0.0001 & 0.0062 & 0.0001 & 0.0052 \\
\hline $1-3$ & 0.0237 & 0.0240 & 0.0001 & 0.0060 & 0.0001 & 0.0050 \\
\hline $2-4$ & 0.0218 & 0.0221 & 0.0001 & 0.0055 & 0.0001 & 0.0046 \\
\hline $3-5$ & 0.0241 & 0.0244 & 0.0001 & 0.0061 & 0.0001 & 0.0051 \\
\hline $3-6$ & 0.0290 & 0.0293 & 0.0001 & 0.0074 & 0.0001 & 0.0062 \\
\hline $4-7$ & 0.0213 & 0.0216 & 0.0001 & 0.0054 & 0.0001 & 0.0045 \\
\hline $4-8$ & 0.0204 & 0.0206 & 0.0000 & 0.0052 & 0.0000 & 0.0043 \\
\hline $5-9$ & 0.0239 & 0.0242 & 0.0001 & 0.0061 & 0.0001 & 0.0051 \\
\hline $6-10$ & 0.0282 & 0.0285 & 0.0001 & 0.0071 & 0.0001 & 0.0060 \\
\hline $7-11$ & 0.0171 & 0.0173 & 0.0000 & 0.0043 & 0.0000 & 0.0036 \\
\hline $8-12$ & 0.0219 & 0.0222 & 0.0001 & 0.0056 & 0.0001 & 0.0047 \\
\hline $10-13$ & 0.0232 & 0.0235 & 0.0001 & 0.0059 & 0.0001 & 0.0049 \\
\hline $10-14$ & 0.0262 & 0.0265 & 0.0001 & 0.0067 & 0.0001 & 0.0056 \\
\hline $11-15$ & 0.0176 & 0.0178 & 0.0000 & 0.0045 & 0.0000 & 0.0037 \\
\hline $11-16$ & 0.0241 & 0.0243 & 0.0001 & 0.0061 & 0.0001 & 0.0051 \\
\hline $12-17$ & 0.0220 & 0.0223 & 0.0001 & 0.0056 & 0.0001 & 0.0047 \\
\hline $13-18$ & 0.0223 & 0.0226 & 0.0001 & 0.0057 & 0.0001 & 0.0047 \\
\hline $14-19$ & 0.0281 & 0.0285 & 0.0001 & 0.0071 & 0.0001 & 0.0060 \\
\hline $16-20$ & 0.0249 & 0.0252 & 0.0001 & 0.0063 & 0.0001 & 0.0053 \\
\hline
\end{tabular}

TABLE A-1B

LiNE SECTION DATA $(\Omega)-21$-BUS Circuit

\begin{tabular}{|c|c|c|c|c|c|c|}
\hline $\begin{array}{c}\text { Line } \\
\text { Section }\end{array}$ & $\mathrm{Rbb}$ & $\mathrm{Xbb}$ & $\mathrm{Rbc}$ & $\mathrm{Xbc}$ & $\mathrm{Rcc}$ & $\mathrm{Xcc}$ \\
\hline $1-2$ & 0.0243 & 0.0246 & 0.0001 & 0.0082 & 0.0243 & 0.0246 \\
\hline $1-3$ & 0.0237 & 0.0240 & 0.0001 & 0.0080 & 0.0237 & 0.0240 \\
\hline $2-4$ & 0.0218 & 0.0221 & 0.0001 & 0.0073 & 0.0218 & 0.0221 \\
\hline $3-5$ & 0.0241 & 0.0244 & 0.0001 & 0.0081 & 0.0241 & 0.0244 \\
\hline $3-6$ & 0.0290 & 0.0293 & 0.0001 & 0.0097 & 0.0290 & 0.0293 \\
\hline $4-7$ & 0.0213 & 0.0216 & 0.0001 & 0.0072 & 0.0213 & 0.0216 \\
\hline $4-8$ & 0.0204 & 0.0206 & 0.0000 & 0.0068 & 0.0204 & 0.0206 \\
\hline $5-9$ & 0.0239 & 0.0242 & 0.0001 & 0.0080 & 0.0239 & 0.0242 \\
\hline $6-10$ & 0.0282 & 0.0285 & 0.0001 & 0.0095 & 0.0282 & 0.0285 \\
\hline $7-11$ & 0.0171 & 0.0173 & 0.0000 & 0.0058 & 0.0171 & 0.0173 \\
\hline $8-12$ & 0.0219 & 0.0222 & 0.0001 & 0.0074 & 0.0219 & 0.0222 \\
\hline $10-13$ & 0.0232 & 0.0235 & 0.0001 & 0.0078 & 0.0232 & 0.0235 \\
\hline $10-14$ & 0.0262 & 0.0265 & 0.0001 & 0.0088 & 0.0262 & 0.0265 \\
\hline $11-15$ & 0.0176 & 0.0178 & 0.0000 & 0.0059 & 0.0176 & 0.0178 \\
\hline $11-16$ & 0.0241 & 0.0243 & 0.0001 & 0.0081 & 0.0241 & 0.0243 \\
\hline $12-17$ & 0.0220 & 0.0223 & 0.0001 & 0.0074 & 0.0220 & 0.0223 \\
\hline $13-18$ & 0.0223 & 0.0226 & 0.0001 & 0.0075 & 0.0223 & 0.0226 \\
\hline $14-19$ & 0.0281 & 0.0285 & 0.0001 & 0.0094 & 0.0281 & 0.0285 \\
\hline $16-20$ & 0.0249 & 0.0252 & 0.0001 & 0.0084 & 0.0249 & 0.0252 \\
\hline
\end{tabular}

TABLE A-2

THREE-PHASE LOAD - 21-BUS CIRCUIT

\begin{tabular}{|c|c|c|c|c|c|c|}
\cline { 2 - 7 } \multicolumn{1}{c|}{} & \multicolumn{2}{c|}{ Phase $a$} & \multicolumn{2}{c|}{ Phase $b$} & \multicolumn{2}{c|}{ Phase $c$} \\
\hline Node & W & Var & W & Var & W & Var \\
\hline 1 & 2209.7 & 941.3 & 255.4 & 108.8 & 0.0 & 0.0 \\
\hline 2 & 1425.9 & 607.4 & 0.0 & 0.0 & 219.5 & 93.5 \\
\hline 3 & 2223.9 & 947.4 & 231.9 & 98.8 & 231.9 & 98.8 \\
\hline 4 & 3440.4 & 1465.6 & 228.0 & 97.1 & 228.0 & 97.1 \\
\hline 5 & 2742.4 & 1168.2 & 0.0 & 0.0 & 0.0 & 0.0 \\
\hline 7 & 0.0 & 0.0 & 201.3 & 85.7 & 500.4 & 213.2 \\
\hline 9 & 1251.4 & 533.1 & 566.1 & 241.2 & 201.3 & 85.7 \\
\hline 10 & 775.9 & 330.5 & 822.1 & 350.2 & 0.0 & 0.0 \\
\hline 11 & 885.3 & 377.2 & 0.0 & 0.0 & 0.0 & 0.0 \\
\hline 12 & 1584.6 & 675.0 & 0.0 & 0.0 & 306.5 & 130.6 \\
\hline 13 & 681.0 & 290.1 & 0.0 & 0.0 & 442.7 & 188.6 \\
\hline 14 & 131.3 & 56.0 & 131.3 & 56.0 & 0.0 & 0.0 \\
\hline 15 & 627.5 & 267.3 & 276.7 & 117.9 & 276.7 & 117.9 \\
\hline 17 & 912.1 & 388.6 & 0.0 & 0.0 & 0.0 & 0.0 \\
\hline 18 & 1090.9 & 464.7 & 0.0 & 0.0 & 0.0 & 0.0 \\
\hline 19 & 793.5 & 338.0 & 73.6 & 31.3 & 0.0 & 0.0 \\
\hline 20 & 541.2 & 230.5 & 0.0 & 0.0 & 0.0 & 0.0 \\
\hline
\end{tabular}

TABLE A-3

LINE SECTION DATA - 29-BUS CIRCUIT

\begin{tabular}{|c|c|c|c|c|c|}
\hline $\begin{array}{c}\text { Line } \\
\text { Section }\end{array}$ & $\begin{array}{c}\text { Length } \\
(\mathrm{km})\end{array}$ & $\begin{array}{c}3 \phi \\
\text { Impedance } \\
\text { Matrix }\end{array}$ & $\begin{array}{c}\text { Line } \\
\text { Section }\end{array}$ & $\begin{array}{c}\text { Length } \\
(\mathrm{km})\end{array}$ & $\begin{array}{c}3 \phi \\
\text { Impedance } \\
\text { Matrix }\end{array}$ \\
\hline $1-2$ & 0.017 & $\mathrm{Z}_{1}$ & $13-16$ & 0.030 & $\mathrm{Z}_{2}$ \\
\hline $1-3$ & 0.023 & $\mathrm{Z}_{1}$ & $14-17$ & 0.020 & $\mathrm{Z}_{3}$ \\
\hline $2-4$ & 0.015 & $\mathrm{Z}_{1}$ & $15-18$ & 0.011 & $\mathrm{Z}_{3}$ \\
\hline $3-5$ & 0.011 & $\mathrm{Z}_{1}$ & $16-19$ & 0.031 & $\mathrm{Z}_{2}$ \\
\hline $4-6$ & 0.022 & $\mathrm{Z}_{2}$ & $17-20$ & 0.007 & $\mathrm{Z}_{2}$ \\
\hline $4-7$ & 0.008 & $\mathrm{Z}_{1}$ & $17-21$ & 0.010 & $\mathrm{Z}_{3}$ \\
\hline $4-8$ & 0.008 & $\mathrm{Z}_{2}$ & $17-22$ & 0.032 & $\mathrm{Z}_{2}$ \\
\hline $5-9$ & 0.010 & $\mathrm{Z}_{3}$ & $18-23$ & 0.005 & $\mathrm{Z}_{2}$ \\
\hline $5-10$ & 0.015 & $\mathrm{Z}_{1}$ & $18-24$ & 0.019 & $\mathrm{Z}_{3}$ \\
\hline $5-11$ & 0.019 & $\mathrm{Z}_{3}$ & $18-25$ & 0.013 & $\mathrm{Z}_{2}$ \\
\hline $6-12$ & 0.019 & $\mathrm{Z}_{2}$ & $23-26$ & 0.028 & $\mathrm{Z}_{2}$ \\
\hline $8-13$ & 0.029 & $\mathrm{Z}_{2}$ & $25-27$ & 0.019 & $\mathrm{Z}_{2}$ \\
\hline $9-14$ & 0.028 & $\mathrm{Z}_{3}$ & $27-28$ & 0.020 & $\mathrm{Z}_{2}$ \\
\hline $11-15$ & 0.031 & $\mathrm{Z}_{3}$ & $28-29$ & 0.023 & $\mathrm{Z}_{2}$ \\
\hline
\end{tabular}

$$
Z_{1}=\left[\begin{array}{lll}
1.1756+j 0.7207 & 0.2123+j 0.4138 & 0.2031+j 0.3721 \\
0.2123+j 0.4138 & 1.1457+j 0.7552 & 0.1897+j 0.4401 \\
0.2031+j 0.3721 & 0.1897+j 0.4401 & 1.1295+j 0.7741
\end{array}\right] \Omega / \mathrm{km}
$$

$$
\begin{aligned}
& Z_{2}=\left[\begin{array}{lll}
1.2697+j 0.7982 & 0.2046+j 0.4330 & 0.1959+j 0.3903 \\
0.2046+j 0.4330 & 1.2414+j 0.8295 & 0.1832+j 0.4569 \\
0.1959+j 0.3903 & 0.1832+j 0.4569 & 1.2261+j 0.8467
\end{array}\right] \Omega / \mathrm{km} \\
& Z_{3}=\left[\begin{array}{lll}
0.9154+j 0.7936 & 0.2046+j 0.4330 & 0.1959+j 0.3903 \\
0.2046+j 0.4330 & 0.8871+j 0.8249 & 0.1832+j 0.4569 \\
0.1959+j 0.3903 & 0.1832+j 0.4569 & 0.8718+j 0.8421
\end{array}\right] \Omega / \mathrm{km}
\end{aligned}
$$

TABLE A-4

THREE-PHASE LOAD - 29-BUS CIRCUIT

\begin{tabular}{|c|c|c|c|c|c|c|}
\cline { 2 - 7 } \multicolumn{1}{c|}{} & \multicolumn{2}{c|}{ Phase $a$} & \multicolumn{2}{c|}{ Phase $b$} & \multicolumn{2}{c|}{ Phase $c$} \\
\hline Node & W & Var & W & Var & W & Var \\
\hline 3 & 451.4 & 148.4 & 209.7 & 68.9 & 0.0 & 0.0 \\
\hline 6 & 0.0 & 0.0 & 18.1 & 5.9 & 329.2 & 108.2 \\
\hline 8 & 641.7 & 210.9 & 397.9 & 130.8 & 504.9 & 166.0 \\
\hline 9 & 188.2 & 61.9 & 268.8 & 88.4 & 0.0 & 0.0 \\
\hline 10 & 166.0 & 54.6 & 97.2 & 31.9 & 349.3 & 114.8 \\
\hline 12 & 262.5 & 86.3 & 142.4 & 46.8 & 120.1 & 39.5 \\
\hline 13 & 326.4 & 107.3 & 441.0 & 144.9 & 331.3 & 108.9 \\
\hline 14 & 147.2 & 48.4 & 310.4 & 102.0 & 127.1 & 41.8 \\
\hline 15 & 377.1 & 123.9 & 348.6 & 114.6 & 403.5 & 132.6 \\
\hline 16 & 1044.4 & 343.3 & 185.4 & 389.6 & 20.1 & 335.3 \\
\hline 19 & 330.6 & 108.7 & 562.5 & 184.9 & 754.2 & 247.9 \\
\hline 20 & 0.0 & 0.0 & 236.8 & 77.8 & 216.0 & 71.0 \\
\hline 21 & 311.1 & 102.3 & 544.4 & 178.9 & 234.7 & 77.1 \\
\hline 22 & 294.4 & 96.8 & 59.7 & 19.6 & 0.0 & 0.0 \\
\hline 23 & 112.5 & 37.0 & 112.5 & 37.0 & 0.0 & 0.0 \\
\hline 24 & 113.9 & 37.4 & 0.0 & 0.0 & 0.0 & 0.0 \\
\hline 25 & 0.0 & 0.0 & 170.8 & 56.1 & 170.8 & 56.1 \\
\hline 26 & 570.8 & 187.6 & 273.6 & 89.9 & 0.0 & 0.0 \\
\hline 27 & 507.6 & 166.8 & 291.0 & 95.6 & 343.1 & 112.8 \\
\hline 28 & 144.4 & 47.5 & 366.7 & 120.5 & 569.4 & 187.2 \\
\hline 29 & 118.1 & 38.8 & 118.1 & 38.8 & 0.0 & 0.0 \\
\hline
\end{tabular}

\section{ACKNOWLEDGMENT}

The authors would like to express their gratitude to Prof. Janusz Bialek for his assistance in and support. 


\section{REFERENCES}

[1] A. Invernizzi, B. Buchholz, M. Stubbe, N. Jenkins, B. Dowd, and M. Ceraolo, 2004, "Distribution Systems and Dispersed Generation: a New Focus for CIGRE", Electra, no. 213, 17-21.

[2] N. Jenkins, R. Allan, P. Crossley, D. Kirschen, and G. Strbac, Embedded Generation, IEE Power and Energy Series 31, London: The Institution of Electrical Engineers, 2000.

[3] P. P. Barker and R. W. de Mello, "Determining the impact of distributed generation on power systems: Part 1 - Radial Distribution Systems", Proceedings of the 2000 IEEE Power Engineering Society Summer Meeting, pp. 1645-1656.

[4] N. Hadjsaid, J.-F. Canard, and F. Dumas, "Dispersed generation impact on distribution networks", IEEE Computer Applications in Power, vol. 12, no. 2, 1999, pp. 22-28.

[5] J. A. P. Lopes, "Integration of dispersed generation on distribution networks-impact studies", in Proceedings of the 2002 IEEE Power Engineering Society Winter Meeting, vol. 1, pp. 323-328.

[6] L. F. Ochoa, A. Padilha-Feltrin, and G. Harrison, "Evaluating Distributed Generation Impacts with a Multiobjective Index", IEEE Trans. on Power Delivery, in press. Digital Object Identifier 10.1109/TPWRD.2005.860262.

[7] Southwest Windpower (http://www.windenergy.com/), April 2006.

[8] Fortis Windenergy (http://www.fortiswindenergy.com/eng/index.asp), Aug April 2006.

[9] Bergey Windpower Co. (http://bergey.com/), April 2006.

[10] Renewable Devices (http://www.renewabledevices.com), April 2006.

[11] Wind Energy Solutions (http://www.windenergysolutions.nl), April 2006.

[12] Department of Trade and Industry, "System Integration of Additional Microgeneration", 2005.

http://www.dti.gov.uk/renewables/publications/pdfs/dgcg00028rep.pdf.

[13] Rade M. Ciric, Antonio Padilha Feltrin, Luis F. Ochoa, "Power Flow in Four-Wire Distribution Networks - General Approach", Power Systems, IEEE Transactions on vol. 18, Issue 4, Nov. 2003, pp. 1283 - 1290.

\section{BIOGRAPHIES}

Petros P. Kritharas graduated from the Electrical Engineering Dept., Technological Educational Institute of Patras, Greece in 2004. He obtained the M.Sc. degree in Sustainable Energy Systems in September, 2005 from the University of Edinburgh. His interests include distributed generation.

Luis F. Ochoa (S'01) graduated from the National Engineering University (U.N.I.) - Lima, Peru, in 2000. He obtained the M.Sc. degree from UNESP Ilha Solteira, Brazil in 2003. Currently he is towards the Ph.D. at UNESP Ilha Solteira, Brazil. He spent a year as a Visiting Postgraduate Researcher at the School of Engineering and Electronics, University of Edinburgh, U.K. His research interests are distribution system analysis and distributed generation.

Konstantinos D. Papastergiou ( $\mathrm{S}^{\prime} 01$ ) graduated from the Electronic Engineering Dept., Technological Educational Institute of Crete, Greece in 2000. He is currently pursuing a $\mathrm{PhD}$ in the University of Edinburgh, Institute for Energy Systems under a research contract with British Aerospace (BAE Systems), from where he receives a scholarship. His main interests include the manufacture and operation of sophisticated power electronic systems for the transmission of electrical energy into distribution networks and renewable energy.

Gareth P. Harrison (M'02) is a Lecturer in Energy Systems in the School of Engineering and Electronics, University of Edinburgh. In addition to his work on integrating distributed generation into electricity networks, he is involved in analysing the impact of climate change on the electricity industry with emphasis on hydropower, marine energy and electricity demand. Dr. Harrison is a member of the Institution of Electrical Engineers, UK and a Chartered Engineer. 